\title{
IMPLEMENTASI FREE OPEN SOURCE E-COMMERCE (FOSE) UNTUK MENDUKUNG PEMASARAN DIGITAL PADA UMKM JAMUR TIRAM
}

\author{
Haryono Setiadi ${ }^{1}$, Ristu Saptono ${ }^{2}$ dan Pringgo Widyo ${ }^{3}$ \\ ${ }^{1}$ Fakultas MIPA Universitas Sebelas Maret \\ ${ }^{2}$ Fakultas MIPA Universitas Sebelas Maret \\ ${ }^{3}$ Fakultas Teknik Universitas Sebelas \\ hsd@staff.uns.ac.id
}

\begin{abstract}
Abstrak
Desa Tambak Boyolali adalah sentra usaha mikro kecil menengah (UMKM) jamur tiram. Produk yang dihasilkan UMKM tersebut adalah baglog, jamur tiram segar, keripik jamur tiram dan bio briket. Produk-produk yang dihasilkan di desa tersebut pada dasarnya telah memiliki kualitas yang baik, karena telah diproduksi sesuai dengan Petunjuk Operasional Standar (POS). Akan tetapi UMKM tersebut masih memerlukan dukungan untuk pemasarannya. Selama ini para pembudidaya tersebut cenderung memasarkan produknya kepada pengepul di sekitar Desa Tambak dengan harga yang kurang kompetitif. Hal ini berdampak UMKM di wilayah tersebut sulit berkembang. Diperlukan dukungan pengetahuan dan ketrampilan untuk mendukung sentra ini agar berkembang. Upaya dilakukan untuk mengatasi permasalahan tersebut dengan sosialisasi dan pelatihan kepada anggota UMKM tentang penjualan dengan memanfaatan media internet (facebook dan instragram). Disamping itu, para pembudidaya juga diberikan dukungan berupa pendampingan untuk melakukan pemasaran di toko online khusus UMKM seperti bukalapak.com dan tokopedia.com. Sentra UMKM juga didukung dengan pembuatan website khusus pemasaran produk sentra jamur tiram dengan software berbasis Free Open source E-Commerce (FOSE) yaitu software woocommerce yang bisa diakses pada laman http://tokojamur.com. Hasil dari kegiatan ini anggota UMKM jamur tiram memiliki pengetahuan dan ketrampilan untuk memasarkan produknya melalui media online (E-Commerce) yaitu Facebook, Instragram, bukalapak.com, tokopedia.com serta website pemasaran UMKM jamur tiram yang telah dibangun.
\end{abstract}

Kata Kunci : E-commerce, FOSE, Jamur Tiram, UMKM

\section{PENDAHULUAN}

Usaha Mikro Kecil dan Menengah (UMKM) merupakan penggerak utama ekonomi nasional. Oleh karena itu UMKM perlu mendapat perhatian, baik dari pemerintah maupun dari institusi pendidikan. Dalam menjalankan usaha, banyak kendala yang dihadapi oleh pelaku UMKM. Beberapa kendala yang dihadapi oleh UMKM adalah keterbatasan infrastruktur, akses permodalan, lemahnya kompetensi SDM dan terbatasnya akses informasi, termasuk akses informasi pasar. Pelaku UMKM perlu dibekali pengetahuan dan keterampilan yang memadai terkait dengan jenis usaha yang dilakukan dan pengetahuan keterampilan menyangkut pemanfaatan teknologi informasi. (Izzahuddin, 2010).

Penguasaan pemanfaatan teknologi informasi oleh pelaku Usaha Mikro Kecil dan Menengah (UMKM) merupakan salah satu kunci dalam mendapatkan akses informasi pemasaran. Penguasaan teknologi oleh pelaku UMKM yang masih lemah menjadikan pengelolaan usaha selama ini dilakukan dengan cara tradisional, termasuk

Teknologi Informasi dan Komunikasi 
pemasarannya. Pemasaran dilakukan dengan memasarkan dari mulut-ke-mulut (word to mouth) atau dengan membuka kios konvensional. Adanya pemanfaatan teknologi, komunikasi dan informasi dapat memberikan kemudahan atau akses yang lebih baik bagi masyarakat dalam kegiatan pemasarannya, yaitu dengan electronic commerce (e-commerce).

E-commerce merupakan konsep yang bisa digambarkan sebagai proses jual beli barang pada internet atau proses jual beli atau pertukaran produk, jasa, dan informasi melalui jaringan informasi termasuk internet (Turban, Lee, King, Chung, 2010 dalam buku Suyanto, 2005). Manfaat dan keuntungan menggunakan e-commerce adalah untuk media promosi dalam rangka meningkatkan volume penjualan (Jansen, 2006; Supardi, 2009).

Masalah pemasaran produk juga dialami oleh UMKM masyarakat pembudidaya jamur tiram di Boyolali Desa Tambak Kecamatan Mojosongo Boyolali. Wilayah ini merupakan penghasil jamur tiram putih. Desa ini berada pada ketinggian $400 \mathrm{~m}$ dpl, dengan iklim tropis, kisaran suhu $25^{\circ} \mathrm{C}-28^{\circ} \mathrm{C}$ dan kelembaban udara mencapai $88 \%$ (http://www.boyolalikab.go.id/). Pada kondisi ini, wilayah ini sangat sesuai untuk tumbuh kembang jamur tiram putih tanpa perlu lagi dilakukan rekayasa lingkungan untuk mengkondisikan pembudidayaan jamur tiram putih.

Berdasarkan hasil eksplorasi di Desa Tambak, Mojosongo Boyolali, diperoleh informasi bahwa produk para pembudidaya jamur yang terdiri dari media baglog yang berisi bibit jamur tiram, jamur tiram segar, keripik jamur tiram, dan bio briket telah memiliki kualitas yang baik. Hal ini karena para pembudidaya tersebut telah menerapkan prosedur operasi standar (POS) dalam produksi produkproduknya. POS tersebut merupakan hasil kegiatan pendampingan dari tim Pusat Kajian dan Pengembangan Teknologi dan Kolaborasi Industri ( PKPTKI) Lembaga Penelitian dan Pengabdian Masyarakat (LPPM) Universitas Sebelas Maret (UNS) pada tahun 2014 oleh Damayanti dkk, melalui skema program Ipteks Bagi Masyakarat (IbM). Namun demikian, produk-produk hasil UMKM ini masih dipasarkan secara konvensional, dengan menitipkan kepada pengepul di Boyolali dengan harga yang tidak kompetitif. Padahal fakta di lapangan, potensi pasar berbagai produk jamur tiram ini sangat luas. Saat ini jamur tiram merupakan primadona yang banyak dicari konsumen. Minat yang tinggi dari konsumen membuat pasar jamur tiram menjadi besar, dan mengalahkan jamur pipih lain seperti jamur kuping, yang telah lebih dulu populer (Damayanti, 2013). Salah satu faktor kepopuleran tersebut, karena Jamur tiram putih (Pleurotus ostreatus) merupakan salah satu jamur edibel (jamur pangan) yang telah dikonsumsi secara luas oleh masyarakat di seluruh dunia, dengan nilai gizi dan daya cerna yang tinggi (Damayanti, 2016).

Berdasarkan permasalahan ini, untuk mendukung para pembudidaya jamur tiram dalam pemasaran produk-produk yang dihasilkan oleh UMKM jamur tiram di Desa Tambak Mojosongo Boyolali, dilakukan kegiatan Program Kemitraan Masyarakat Riset Group Sistem Informasi Prodi Informatika MIPA UNS pada tahun 2018 yang fokus pada pemasaran dengan sistem on-line serta pemanfaatan Free Open Source E-commerce (FOSE).

Selama ini para pembudidaya anggota UMKM Desa Tambak telah menerapkan prosedur operasi standar (POS) hasil dari tim PKPTKI LPPM UNS untuk proses produksi, sehingga hasil produknya berkualitas baik. Namun dari aspek pemasaran produk masih lemah. Untuk produk jamur tiram dan baglog biasanya dibeli langsung oleh pengepul yang datang kepada pembudidaya jamur. Untuk produk keripik jamur dan bio briket dipasarkan dengan metode word to mount (dari mulut-ke-mulut) dengan cara menitipkan ke kioskios di Desa Tambak, Boyolali dan produksi berdasarkan pesanan. Cara pemasaran yang sifatnya tradiosional tersebut belum optimal, karena pembeli hanya sebatas yang mengetahui lokasinya dan sebatas masyarakat di sekitar Desa Tambak Boyolali. Pemasaran dengan metode konvensional memerlukan biaya tinggi, misalnya membuka cabang baru, ikut pameran, pembuatan dan penyebaran brosur dan sebagainya.

Uraian permasalahan petani jamur tiram di Desa Tambak Boyolali dirinci dengan menggunakan diagram fishbone, agar teridentifikasi akar masalahnya. Hal ini yang akan menjadi dasar dalam merumuskan upaya-upaya penyelesaian masalah. 
Diagram fishbone permasalahan dan akarnya ditampilkan pada Gambar 1.

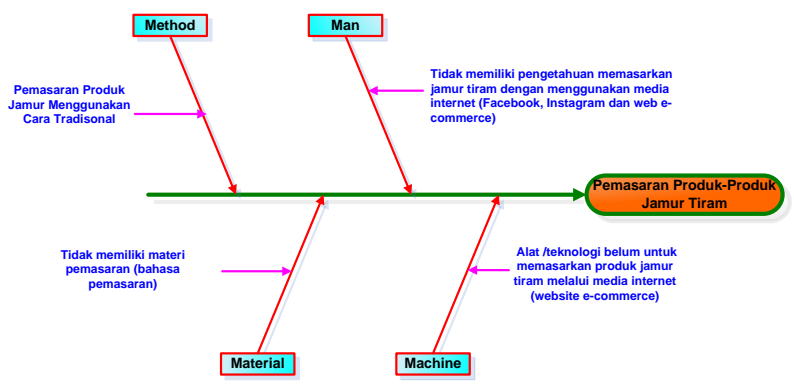

Gambar 1. Diagram Fishbone Permasalahan dan Akarnya

Berkaitan dengan permasalahan tersebut selanjutnya dilakukan diskusi dengan para pembudidaya jamur, untuk merumuskan penyelesaian masalah yang disepakati. Hal ini penting, agar upaya-upaya penyelesaian masalah yang dilakukan disetujui dan didukung, sehingga solusi yang diberikan nantinya dapat dijalankan dan ditindaklanjuti secara berkelanjutan dan mandiri oleh para pembudidaya jamur tiram di desa tersebut. Tanpa ada kesepakatan, kemauan dan komitmen dari para pembudidaya jamur tiram tersebut, perbaikan yang diberikan akan bersifat snap shoot dan tidak akan berkelanjutan.

\section{METODE}

Penyelesaian masalah bagi petani jamur tiram, dilakukan melalui dukungan teknologi dan dukungan manajemen. Upaya tersebut dilakukan dengan secara aktif mengikutsertakan dan memberdayakan pembudidaya jamur tiram. Secara spesifik, metode yang akan diaplikasikan bagi petani jamur tiram meliputi solusi teknologi dan manajemen.

\section{Solusi Permasalahan Teknologi}

Untuk mendukung pemasaran produkproduk yang dihasilkan oleh pembudidaya jamur, dilakukan dengan 1) Sosialisasi dan pelatihan pemasaran dengan memanfaatkan media sosial Facebook dan Instragram yang diselenggarakan selama 1 hari. 2) Sosialisasi dan pelatihan pemasaran dengan memanfaatkan situs komersial Bukalapak.com dan Tokopedia.com selama 1 hari. 3) Pembuatan software pemasaran berbasis Free Open Source E-Commerce (FOSE) menggunakan software woocommerce khusus untuk pembudidaya jamur tiram Desa Tambak dengan alamat url http://tokojamur.com.

\section{Solusi Permasalahan Manajemen}

Implementasi teknologi di masyarakat, harus dibarengi dengan dukungan manajemen (pengelolaan) teknologi tersebut. Berkaitan dengan permasalahan manajemen ini, solusi yang diberikan adalah : 1) Pendampingan kepada UMKM petani jamur terkait dengan pemasaran melalui media internet (online) (facebook dan instragram) beserta dengan pelatihan proses bisnisnya (bahasa pemasaran, foto produk, rekap data, transaksi online, dan pengiriman), yang dilakukan setelah sosialisasi dan pelatihan. Kegiatan ini dilaksanakan selama 1 bulan. 2) Pendampingan untuk melakukan pemasaran di toko online khusus UMKM seperti bukalapak.com dan tokopedia.com, yang terdiri dari proses awal hingga transaksi order produk. Kegiatan ini dilakukan setelah sosialisasi dan pelatihan. Dilaksanakan selama 1 bulan. 3) Pendampingan penggunaan software berbasis Free Open source ECommerce (FOSE) menggunakan woocommerce yang terdiri dari pengisian konten web, upload foto produk, dan merawat web. Kegiatan ini dilaksanakan selama 1 bulan.

Secara rinci, metode dan tahapan dalam penyelesaian permasalahan mitra digambarkan pada Gambar 2.
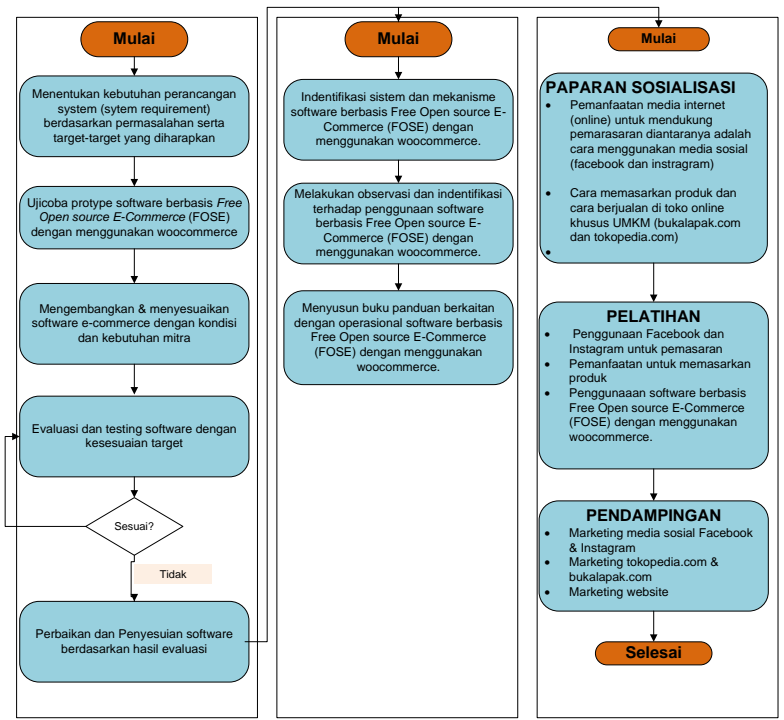

Teknologi Informasi dan Komunikasi 


\section{HASIL DAN PEMBAHASAN}

Berikut akan diuraikan hasil dari kegiatan program kemitraan antara tim Riset Grup Sistem Informasi Fakultas MIPA UNS dengan UMKM jamur tiram di Desa Tambak Boyolali.

\section{Sosialisasi dan Pelatihan Pemasaran Online (E-Commerce)}

Kegiatan sosialisasi dan pelatihan pemasaran on-line dilakukan dengan 2 tahap. Tahapan pertama adalah sosialisasi dan pemasaran dengan media sosial facebook dan instagram. Kegiatan ini dilaksanakan pada tanggal 27 - 28 Juli 2018. Hari pertama dilakukan paparan umum tentang mekanisme pemasaran di era digital. Materi pada hari pertama meliputi : pengenalan digital marketing, perubahan perilaku masyarakat, dan manfaat penggunaan digital marketing untuk mendukung pemasaran. Beberapa contoh konten materi ini ditampilkan pada Gambar 3.

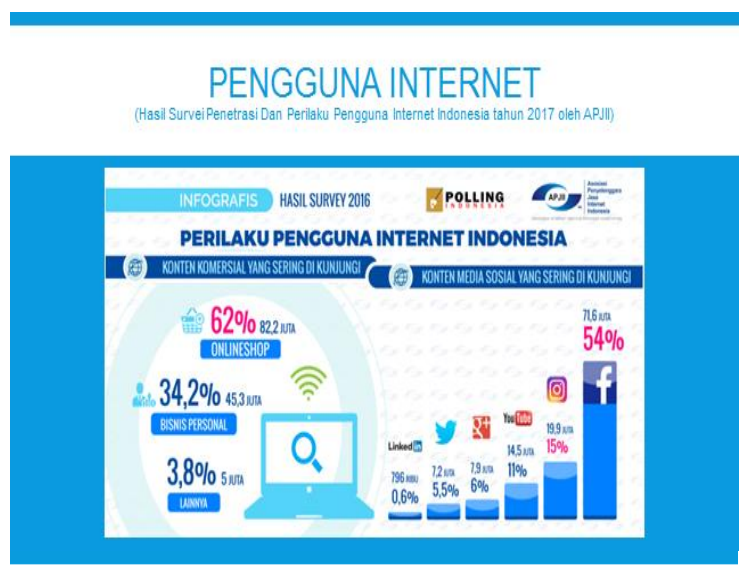

\section{MANFAATDIGITAL MARKETING}

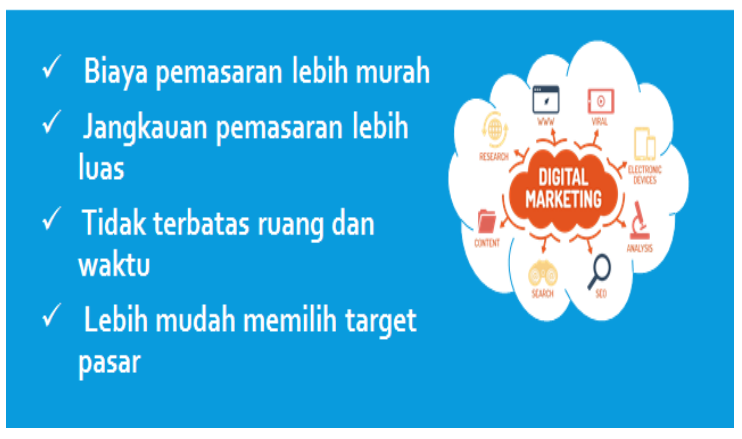

\section{Gambar 3. Contoh Materi Sosialisasi}

Pada hari kedua, kegiatan dilakukan dengan membimbing pembudidaya untuk memperkaya konten promosi di media Facebook dan instagram. Para pembudidaya jamur ini telah mengenal kedua media sosial tersebut, namun belum pernah mempergunakan fasilitasnya yang berkaitan untuk promosi produk-produknya. Berkaitan dengan hal tersebut, pada kegiatan ini para pembudidaya dipaparkan bagaimana cara mengeksplorasi fungsifungsi yang ada di Facebook dan Instagram untuk memasaran produknya.

Tahapan berikutnya adalah sosialisasi dan pelatihan pemasaran dengan pemanfaatan media online bukalapak.com dan tokopedia.com. Pelaksanaan kegiatan ini dilakukan pada tanggal 10 - 11 Agustus 2019. Materi kegiatan dan aktivitas kegiatan ini didokumentasikan pada Gambar 4.

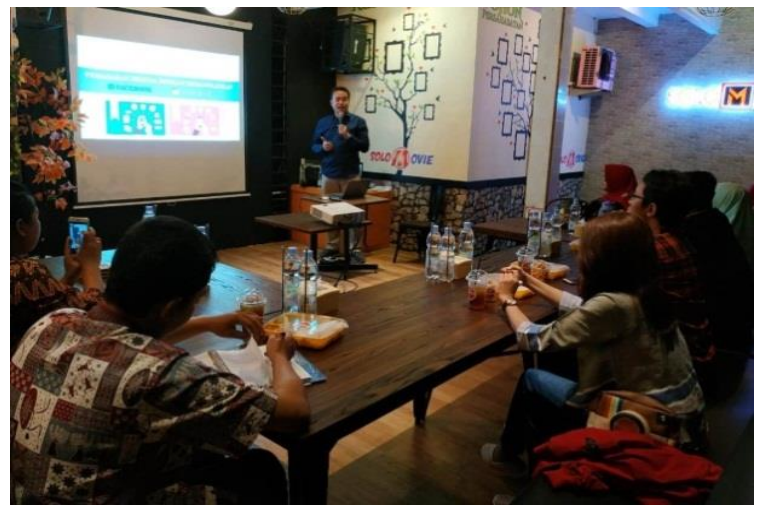

Gambar 4. Dokumentasi Sosialisasi dan Pelatihan

\section{Pembuatan Software E-commorce}

Selain sosialisasi dan pelatihan dengan media sosial dan media online yang telah tersedia. Tim juga melakukan pengembangan website marketing khusus untuk UMKM pembudidaya jamur tiram Desa Tambak Boyolali. Website dibangun dan diimplementasikan adalah berbasis Free Open source E-Commerce (FOSE) menggunakan software woocommerce. Sofware tersebut telah terpasang pada server hosting dan dapat di akses dengan alamat http://tokojamur.com. Tampilan website E-Commerce yang di implementasikan kepada mitra ditampilkan pada Gambar 5. 

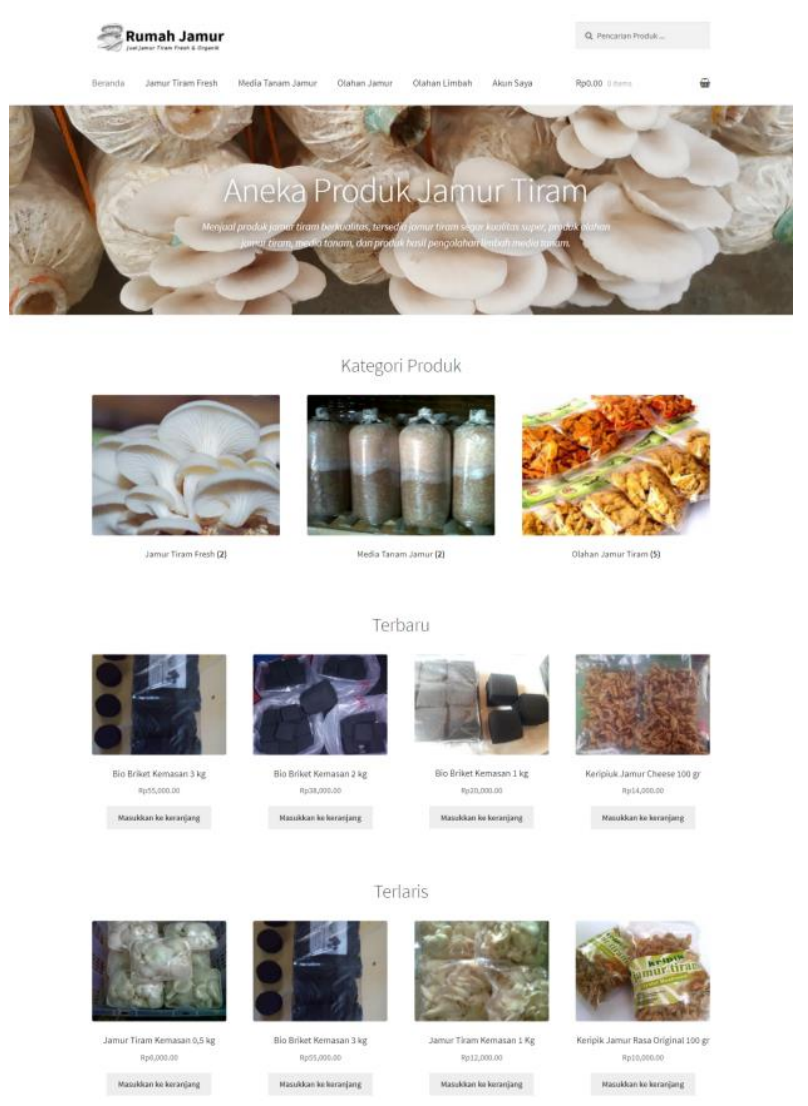

Gambar 5 Tampilan Website Rumah Jamur Untuk Pemasaran UMKM Jamur Tiram Mitra

\section{Pendampingan Pemasaran}

Setelah sosialisasi dan pelatihan pemasaran dengan berbagai media online, aktivitas berikutnya adalah melakukan pendampingan kepada para pembudidaya tersebut, agar pemasaran secara digital dapat konsisten dijalankan. Kedepannya, aktivitas tersebut dilakukan secara mandiri oleh UMKM tersebut. Untuk kegiatan ini, telah disusun buku modul yang nantinya dapat dipergunakan secara mandiri oleh pembudidaya.

\section{KESIMPULAN}

Program kemitraan kepada mitra UMKM jamur tiram di desa Tambak Boyolali telah mendukung pemasaran hasil produk dari pembudidaya jamur di desa tersebut. Melalui sosialisasi, pelatihan dan pendampingan pemasaran dengan media sosial dan media online serta implementasi website e-commerce yang di pasang, pembudidaya jamur dapat menjual produknya tidak hanya di wilayah Boyolali. Saat ini, beberapa pembudidaya telah mengirimkan produknya hingga ke luar Boyolali, walaupun masih terbatas di area Jawa Tengah. Hal ini menjadi indikator positif bahwa para pembudidaya jamur di UMKM Desa Tambak Mojosongo Boyolali dapat mengembangkan usaha ke depannya.

\section{UCAPAN TERIMAKASIH}

Kegiatan program kemitraan masyarakat ini mendapatkan dukungan dana hibah pengabdian masyarakat Lembaga Penelitian dan Pengabdian Masyarakat Universitas Sebelas Maret tahun anggaran 2018.

\section{REFERENSI}

Damayanti, RW., Rosyidi, C., Priadhytama, I., Aisyati, A., (2013)., Penerapan Teknologi Pengering Tenaga Surya (Box Solar Dryer) Untuk Pembudidaya Jamur Tiram, Prosiding Seminar Nasional Pemberdayaan UMKM melalui Teknologi Tepat Guna, Energi Baru dan Terbarukan yang Ramah Lingkungan ISBN : 978 - 979 - 3514-66-6., Politeknik Negeri Semarang.

Damayanti, RW ; Rosyidi, CN ; Priadythama, I ; Aisyati, A, (2014), Alternatif Diversifikasi Pengolahan Jamur Tiram Putih (Pleurotus Ostreatus) menjadi Tepung Jamur), Jurnal Performa, Vol 13, No 2, Tahun 2014, ISSN : 1412-8624

Izzahudin, Ahmad, (2017), Transfer Teknologi "ECommerce" sebagai Solusi Tingkatkan Pangsa Pasar UMKM, Kompasiana https://www.kompasiana.com/ahmad_izzud din_10/

5a24957d59b13028be763e62/transferteknologi-e-commerce-sebagai-solusitingkatkan-pangsa-pasar-umkmimplementasi-pengabdian-dosenuniversitas-panca-marga-kepadamasyarakat diakses pada 17 Februari 2017

Teknologi Informasi dan Komunikasi 
Jauhari, Jaidan, (2010), Upaya Pengembangan Usaha Kecil Dan Menengah (UKM) Dengan Me Manfaatkan E-Commerce, jurnal sistem informasi fakultas ilmu komputer UNSRI, Vol 2 No 1 tahun 2010

Jansen, B.J.,(2006). An Examination Of Searcher's Perceptions Of Nonsponsored And Sponsored Links During E-commerce Web Searching. Journal Of The American Society For Information Science And Technology, 57(14):1949-1961

Jansen, B.J. (2006).The Comparative Effectiveness of Sponsored and Nonsponsored Links for Web E-commerce Queries. ACM Transactions on the Web, Vol. 1, No. 1, Article 3, Publication date: May 2007.

Masyarakat Agribisnis Jamur Indonesia (MAJI)., (2011)., Potensi Bisnis Jamur., http://www.agrinaonline.com/show_article.php?aid=1009, diakses tanggal 17 April 2014 pukul 04:19 WIB.

Supardi, Julian. (2009). Rancang Bangun Collaborative System Pemasaran Hotel Secara on-line Dengan Pendekatan Mediator based. Jurnal Sistem Informasi Fasilkom Unsri Vol 1 No 2, ISSN : 2085-1588

Sumarsih, S., (2010)., Untung Besar Usaha Bibit Jamur Tiram., Penebar Swadaya., Jakarta.

Susanti, W ; Kasmi ; Sari, NY ; Muslihudin, M, (2015), Pengembangan Electronic Commerce Dalam Proses Meningkatkan UKM Pada Dekranasda Kabupaten Pringsewu, Expert-Jurnal Manajemen Sistem Informasi dan Teknologi, Vol 5, No 2 tahun 2015, ISSN : 2088-5555

Suyanto, M, (2015), Pengantar Teknologi Informasi Untuk Bisnis, Andy Offset, Yogyakarta, ISBN : 9797318125 